КРАСОВСКАЯ Наталия Рудольфовна - кандидат психологических наук, Аппарат Государственной думы ФС РФ (125007, Россия, г. Москва, ул. Охотный ряд, 1; goulina@gmail.com)

ГУЛЯЕВ Андрей Анатольевич - кандидат философских наук, доцент Московского государственного университета технологий и управления им. К.Г. Разумовского (ПКУ) (109004, Россия, г. Москва, ул. Земляной Вал, 73; andrey.gulyaev1966@yandex.ru)

\title{
К ВОПРОСУ О СРЕДСТВАХ ПОВЕДЕНЧЕСКОЙ ВОЙНЫ
}

\begin{abstract}
Аннотация. Поведенческие войны имеют свои собственные средства в виде поведенческого оружия. Основой этого оружия выступают технологии манипулирования поведением людей. Методологическим инструментом данной работы выступает метод системного анализа. Различные манипулятивные техники представляют систему, в которых слово играет ключевую роль, а главной их целью является такое поведение людей, которое выгодно для манипуляторов. При этом манипулируемые индивиды находятся в плену иллюзии, что они имеют выбор в принятии решений и выборе стратегии и тактики своего поведения. Важнейшую роль в функционировании манипулятивных техник играет Интернет, в частности социальные сети, мессенджеры, информационные ресурсы и электронные СМИ.

Ключевые слова: поведенческие войны, поведенческое оружие, манипулятивные техники, технология «подталкивания», месседж, эффект «плохих новостей»
\end{abstract}

Введение. Информационные войны современности трансформируются вместе с информационным обществом. Развитие информационных технологий и Интернета, программных средств обработки и использования «больших данных», увеличение быстродействия и мощности суперкомпьютеров, опережающие разработки «искусственного интеллекта» ставят на повестку дня проблему поведенческих войн как разновидности информационных и психологических войн. Как и у всякой войны, у поведенческой войны есть свое оружие [Киселев 2017: 40]. Поведенческое оружие основано на техниках манипуляции индивидуальным и массовым сознанием. Известная формулировка гласит: «Арсенал поведенческих войн как принципиально нового вида информационной войны основан на технологиях манипуляции алгоритмами поведения, привычками, стереотипами деятельности, вложенными в нас социумом в самом широком смысле этого слова. Грубо говоря, инструментарий поведенческих войн состоит в том, чтобы отделить привычку от сложившегося вида деятельности, сформировавшей ее ситуации и использовать поведенческие паттерны для достижения иных целей. Поведенческое оружие - это оружие завтрашнего дня» [Ларина, Овчинский 2015: 30].

Методологической основой работы выступает метод системного анализа. Большинство техник манипуляции посредством месседжей взаимосвязаны и представляют собой определенную систему, вход в которую возможен в любом месте. Ключевую роль в этой системе играет слово, а средством распространения - Интернет. Для наибольшей эффективности техник манипуляции воздействие направлено на целевые аудитории - группы людей, объединенных общими признаками или ради какой-либо цели или задачи.

Pезультаты. В инструментарии поведенческих войн одну из главных ролей играют техники манипулирования, лежащие в основе концепции «подталкивания» человека к нужному для манипулятора поведению. Эти техники создают у человека ложную иллюзию свободы и самостоятельности в принятии решений, хотя это не так. Принятие решений и поведение манипулируемого будет выгодно только манипулятору, т.е. «кукловоду» [Ковалев, Матвиенко 2016: 20]. К таким техникам манипулирования бихевиористского характера можно отне- 
сти использование социальных норм, раскрытие информации, заранее согласованную стратегию, напоминания, правила по умолчанию, облегчение и удобство, заранее высказанное намерение, информирование людей о последствиях их предыдущих выборов, упрощение, стереотипизацию, утверждение, повторение информации, напоминания, дробление информации, срочность сообений, сенсационность информации, эффект «плохих новостей» [Санстейн 2016: 56-57].

Указанные техники манипулирования представляют собой систему, состоящую из ключевых элементов, каждый из которых является структурной единицей, взаимосвязанной с другими единицами многочисленными связями и последовательностью. Поскольку вход в систему осуществляется через любой ее элемент, мы избрали в качестве этого элемента технику манипулирования посредством упрощения.

Упрощение является фундаментальной техникой манипулирования человеком. Массовое сознание активно реагирует на достаточно простые сообщения. В социальных сетях и информационных порталах (например, в Фейсбуке или в ИноСМИ) больше всего лайков собирают достаточно примитивные, зачастую просто неграмотно написанные, но эмоционально насыщенные (чаще всего с негативной коннотацией) сообщения с обильным применением просторечий и жаргонизмов [Кугушева 2016: 17-18].

В целях манипулирования для лучшего понимания и запоминания месседжа информационное содержание его значительно упрощают, примитивизируют. Затем происходит его семантизация, т.е. находят несколько слов (клише, характерные понятия), которыми описывается этот упрощенный по содержанию месседж. «Сообщение должно иметь уровень понятности, соответствующий коэффициенту интеллектуальности примерно на десять пунктов ниже среднего коэффициента того социального слоя, на который рассчитано сообщение» [Шейнов 2010: 244]. С точки зрения психологии это правило объясняется склонностью человека на подсознательном уровне к простым объяснениям (и решениям тоже!) сложных проблем. При процедуре упрощения сообщения коммуникатор должен иметь представление о том, какова его целевая аудитория и насколько высок ее интеллектуальный уровень.

Для целей усиления манипулятивного эффекта упрощение сочетается с другими техниками манипуляции сознанием. Упрощение должно быть в форме утверждения. Следующим шагом является повторение утверждения. Упрощенное сообщение требуется внушить аудитории в краткой, энергичной и впечатляющей форме - в форме утверждения (как приказ - без возражения). Утверждение в месседже означает отказ от обсуждения, поскольку власть человека или идеи, которая может подвергаться обсуждению, теряет всякое правдоподобие. Это означает также просьбу к аудитории, к толпе принять идею без обсуждения, такой какая она есть, без взвешивания «за» и «против» и отвечать «да», не раздумывая [Московичи 2018: 165].

Вслед за утверждением следует повторение месседжа. Повторение информации постепенно внедряется в глубины подсознания, где зарождаются мотивы наших действий. Повторение дает импульс утверждению и превращает его в навязчивую идею. Слыша упрошенные утверждения раз за разом, в различных версиях и по самому разному поводу, в конце концов человек начинает проникаться ими. В то же время повторение возводит обязательный барьер против всякого иного утверждения, всякого противоположного убеждения с помощью возврата без рассуждений тех же слов, образов и позиций. Повторение придает им осязаемость и очевидность, которые заставляют принять их целиком. Повторение становится барьером против отличающихся, а тем более противо- 
положных мнений. С помощью повторения мысль отделяется от своего автора. Она не является более выражением человека, который говорит, но становится выражением предмета, о котором он говорит. Повторение является одним из главных инструментов рекламы и пропаганды.

К числу фундаментальных техник манипулирования сознанием относится и стереотипизация. Стереотипизация как техника манипулирования основана на процессе человеческого восприятия как цепочки рефлексов. Восприятие человеком нового является подгонкой этого нового явления под стереотип - заранее сформированной человеком мыслительной оценки чего-либо, которая может отражаться в соответствующем поведении. Человек должен воспринимать сообщение или месседж без усилий и безоговорочно, без внутренней борьбы и критического анализа. Вот, например, как может выглядеть такой стереотип для западного обывателя: «Русские упорно нарушают все правила, мы же будем упорно придерживаться правил». Стереотип о русских как нарушителях правил и норм еще более закрепляется на бессознательном уровне, на котором же формируется зоологическая по своей сути и социально-политическая по своим проявлениям западная русофобия.

Еще одной техникой манипуляций является дробление информации. Целостная проблема делится на отдельные фрагменты, чтобы читатель не мог связать их воедино и осмыслить всю проблему. Анализируя информацию, преподносимую массе интернет-пользователей электронными СМИ, можно сделать простой вывод. Слишком часто электронные СМИ преподносят какуюлибо проблему не целиком, а частично. Например, преподнося как очередную «Плохую новость» факт роста заболеваемости населения каким-либо недугом, большинство электронных СМИ замалчивают другие фрагменты этой проблемы, такие как улучшение диагностики заболеваемости населения или уменьшение младенческой смертности (последнее связано с выживаемостью самых слабых младенцев и их большей уязвимостью в будущем перед болезнями), и т.д.

Другими средствами манипуляций сознанием являются срочность, сенсационность и эффект «плохих новостей». Эти три, по сути, отдельные манипулятивные техники объединяет следующее: помимо общего внушения, человек оказывается под мощным воздействием ситуативного внушения. Ситуативное внушение обостряется в момент, когда рушится привычная социальная ситуация для человека, даже если это разрушение является чисто виртуальным или сильно преувеличенным реальным. В тот момент, когда срочные (человек не успевает их осмыслить и проверить), сенсационные (эмоционально оглушают, вызывают либо паралич, либо импульсивные действия), «плохие новости» (человек легко подчиняется паническому настроению, подпадает под власть толпы и стихийного коллективного безответственного поведения) атакуют общество, немалое число людей становятся орудиями манипуляторов. В эти моменты критическое восприятие у человека понижено, внушаемость повышена [Кара-Мурза 2015: 344]. Для формирования такого эффекта необходимо создать ситуацию, при которой за относительно короткий период времени на общество выплескивается поток «плохих новостей» о реальных или вымышленных событиях. Здесь также стоит учитывать феномен лавины, когда ком «Плохих новостей» имеет тенденцию к моментальному субъективному нарастанию в силу особенностей человеческой психики и восприятия (повышенный интерес к происшествиям и подсознательное ожидание их).

После техники манипуляции с использованием эффекта «плохих новостей» коммуникаторы реализуют еще одну технику манипуляции индивидуальным и массовым сознанием, которая связана с информированием людей о послед- 
ствиях их предыдущих выборов. Чтобы направить волю людей в нужном для манипулятора направлении, необходимо информировать и напоминать им, что в недавнем прошлом или даже накануне они сделали «неправильный», «плохой» выбор (проголосовали не за того кандидата, не вышли на митинг протеста и т.Д.).

В результате система последовательных техник манипулирования сознанием составляет ядро технологии «подталкивания» человека к нужному для манипулятора поведению.

Выводы. Поведенческое оружие основано на техниках манипулирования поведением человека. Сами техники манипулирования образуют систему, состоящую из элементов, которые по отдельности и в определенном сочетании традиционно применяются в пропаганде, рекламе и т.д. Поведенческое оружие имеет принципиальную новизну в том, что эти элементы используются комплексно в системе техник манипулирования на основе анализа и использования «больших данных» и направлены на целевые аудитории. Каналами распространения такой направленной информации и месседжей являются практически все ресурсы Интернета. Также учитываются особенности целевых аудиторий, в которых манипулятивные месседжи могут передаваться и обсуждаться через непосредственные социальные связи и контакты.

Государство и общество должны разработать такие механизмы, которые могут предотвратить явления с эффектом «плохих новостей», имеющих большой манипулятивный потенциал. Это должно быть сделано не за счет замалчивания «Плохих новостей», что будет иметь только обратный эффект. Также ответственность лежит на электронных СМИ, которые обязаны бороться с фейковыми новостями и публикацией непроверенной информации.

\section{Список литературы}

Кара-Мурза С.Г. 2015. Манипуляция сознанием. Век 21. М.: Алгоритм. 525 с.

Киселев В.А. 2017. К каким войнам необходимо готовить Вооруженные силы России. - Военная мысль. № 3. Март. С. 37-46.

Кугушева А. 2016. От информационных войн к поведенческим. Информационные войны. Т. 37. № 1. С. 11-23.

Ковалев В.И., Матвиенко Ю.А. 2016. «Поведенческая» война как одна из перспективных невоенных угроз безопасности России. - Информационные войны. T. 40. № 4. C. $20-24$.

Ларина Е.С., Овчинский В.С. 2015. Новая военная доктрина США и поведенческие войны. - Информационные войны. Т. 35. № 3. С. 27-33.

Московичи С. 2018. Век толп. Минск: Харвест. 432 с.

Санстейн К. 2016. Иллюзия выбора. Кто принимает решения за нас, и почему это не всегда плохо. М.: Альпина Паблишер. 416 с.

Шейнов В.П. 2010. Манипулирование сознанием. Минск: Харвест. 718 с. 
KRASOVSKAYA Nataliya Rudol'fovna, Cand.Sci. (Psych.), Central Office of the State Duma of the Federal Assembly of the Russian Federation (1 Okhotny Ryad St, Moscow, Russia, 125007; goulina@gmail.com)

GULYAEV Andrei Anatol'evich, Cand.Sci. (Philos.), Associate Professor at the K.G. Razumovsky Moscow State University of Technologies and Management (the First Cossack University) (73 Zemlyanoi Val St, Moscow, Russia, 109004; andrey. gulyaev1966@yandex.ru)

\title{
ON THE QUESTION OF THE MEANS OF BEHAVIORAL WAR
}

\begin{abstract}
Behavioral wars have their own means in the form of behavioral weapons. The basis of these weapons is the technology of manipulation of human behavior. The methodological basis of this work is the method of system analysis. Various manipulative techniques represent a system in which the word plays a key role, and their main purpose is such behavior of people, which is beneficial to manipulators. At the same time, manipulated individuals are held captive by the illusion that they have a choice in decision-making and the choice of strategy and tactics of their behavior. Internet, in particular, social networks, messengers, information resources and electronic media play the most important role in the functioning of manipulative techniques.

Keywords: behavioral warfare, behavioral weapons, manipulative techniques, technology of pushing, message, effect of "bad news"
\end{abstract}

\section{УДК 37.035.4}

КИРСАНОВ Анатолий Иванович - доктор политических наук, директор института «Иностранные языки, современные коммуникации и управление» Московского государственного психолого-педагогического университета (123290, Россия, г. Москва, Шелепихинская наб., 2А, стр. 1; Kirsanov_ai@mail.ru)

\section{ПОЛИТИЧЕСКАЯ БЕЗОПАСНОСТЬ ЛИЧНОСТИ: К МЕТОДОЛОГИИ АНАЛИЗА}

Аннотация. В статье рассматриваются различные научные подходы, методологические основы и сущностные характеристики понятия «политическая безопасность личности». Автор дает собственное определение и утверждает, что в исследовательском плане данное понятие носит междисциплинарный характер. В статье выделяются внутренний и внешний аспекты политической безопасности личности, в основе которых лежат индивидуальные и совокупный политические интересы, подчеркивается значимость политической социализации, особая роль патриотизма как важнейшего ее структурного элемента (критерия). Автор делает обобщающий вывод, что политическая безопасность личности - один из основных приоритетов общественного развития, определяющих цивилизационную зрелость и прогрессивность общества и государства.

Ключевые слова: личность, политическая безопасность, политическая социализация, политические угрозы, государство, общество

П роблема политической безопасности личности не нова. Однако в концептуальном плане, как научная категория, она разработана недостаточно. Как правило, ее сущность и содержание трактуется через совокупность различных социально-политических явлений и имеет несколько направлений. В одних речь идет о системе мер институтов государства и гражданского общества, связанных с обеспечением защиты политических интересов государства, общества и личности; в других в качестве фундаментальной основы рассма- 